\title{
ДИСКУРСИВНЫЕ ГРАНИЦЫ ТЕРРИТОРИИ РОДИТЕЛЬСТВА: АНАЛИЗ КЕЙСА «ПЛОХОЙ МАТЕРИ" В СОЦИАЛЬНЫХ МЕДИА
}

Статья посвящена конструированию приватного и публичного в современных практиках родительства на примере дискуссии по поводу опубликованной в интернете видеозаписи: съемки женщины с плачущим ребенком, сопровожденной осуждающим комментарием. Случай вызвал оживленное обсуждение в социальных сетях и СМИ. Используя метод критического дискурс-анализа, авторы статьи рассматривают конструирование приватности и публичности родительства в дискуссиях, обращая внимание на их гендерную окрашенность. Центральным для работы термином становится «территория родительства»- концепт, взятый из поля (одной из публикаций в СМИ) и развитый с опорой на «территории себя» Ирвинга Гофмана. Как показал анализ, дискурсивные границы территории родительства задаются ситуационными контекстами и ролями участников: они могут маркироваться не только пространством, гендером и самими ролями (мать/посторонний), но и этапами освоения роли («молодая» или «опытная» мать) - от этого зависит чувствительность и проницаемость границ. При этом мы интерпретируем положение матери, которое вырисовывается из дискуссий, как феномен, относящийся к интенсивному материнству. В нем частная ответственность за принятие

Оксана Евгеньевна Дорофеева- магистр социальных наук, младший преподаватель, департамаент социологии, Университет Амстердама, Амстердам, Нидерланды. Электронная почта: o.dorofeeva@uva.nl

Аделя Динаровна Кавеева - аспирантка, кафедра общей и этнической социологии, Казанский федеральный университет, Казань, Россия. Электронная почта: adele.kaveeva@mail.ru

Анна Анатольевна Андреева- к.филол.н., доцент, кафедра журналистики, Тюменский государственный университет, Тюмень, Россия. Электронная почта: a.a.andreeva@utmn.ru

Ольга Евгеньевна Вербилович- магистр социологии, преподаватель, факультет коммуникаций, медиа и дизайна, Национальный исследовательский университет «Высшая школа экономики», Москва, Россия. Электронная почта: overbilovich@hse.ru 
решений по поводу ребенка и его благополучие соседствует с повышенными вниманием и требовательностью по отношению к тому, как матери справляются со своей задачей, в том числе со стороны других матерей. Онлайн-дискуссии по поводу видеоролика становятся местом публичного соревнования между матерями в рамках идеологии интенсивного материнства. Но выстраивается и альтернативный дискурс, конструирующий жесткие границы территории родительства. В заключении мы проблематизируем интенсивное материнство с точки зрения приватности/публичности.

Ключевые слова: родительство, материнство, социальные медиа, дискурс-анализ, онлайн-исследования

DOI: 10.17323/727-0634-2021-19-3-451-464

11 апреля 2018 г. житель Ростова-на-Дону опубликовал в социальной сети видеоролик, в котором он заснял женщину с тремя детьми, один ребёнок плачет и громко кричит. На видео его автор сообщает женщине, что вызвал полицию, а видеоролик отправит в органы опеки, которые «должны разобраться» с ситуацией. Мать отвечает сдержанно и пытается игнорировать мужчину. Однако мужчина продолжает снимать, задает вопросы («Это вообще ваш ребенок?») и утверждает, что ребенок, который «уже минут десять» кричит под окнами - это ненормально. Видеоролик вызвал бурную реакцию в СМИ и социальных медиа. Общественное мнение оказалось на стороне женщины: публикации в СМИ поддерживали мать и осуждали автора видео. Участники родительских онлайн-сообществ требовали удалить видео и заблокировать аккаунт автора ролика. Получив множество негативных комментариев, автор ролика был вынужден удалить пост с видео и закрыть комментарии к своей странице. Медиа для родителей «Нет, это нормально» опубликовало статью, в которой сообщалось, что в общественных пространствах родители «рано или поздно становятся жертвами внезапного вторжения на территорию их родительства со стороны каких-то непонятных людей» (НЭН 2018).

Исследователи отмечают, что в постсоветскую эпоху государство меньше участвует в заботе о детях (Савинская 2011; Шадрина 2017). При этом родительство является объектом активной, пусть и противоречивой государственной политики (Ярская-Смирнова 2010). Социальный антрополог Мишель Ривкин-Фиш отмечает, что российская демографическая политика призывает женщин связывать свои интересы с национальными- повышением уровня рождаемости (Rivkin-Fish 2010). Трудовая активность женщин рассматривается как проблема на пути повышения рождаемости, и потому ориентация женщин на карьеру оценивается отрицательно (Чернова 2012a). Наталия Печерская (2012:323) отмечает, что озабоченность государства вопросами семьи говорит о существовании «устойчивого напряжения» между властью и родителями. Оно проявляется, например, в борьбе общественных 
кампаний против сокращения государственного финансирования программ новых репродуктивных технологий (Чернова 2012b), критике программы материнского капитала (Бороздина и др. 2012). Подобные общественные офлайн и интернет-кампании, а также государственная риторика пронатализма делают приватные практики родительства и особенно материнства в России объектом общественного и государственного внимания.

Фокусом нашего анализа кейса «плохой матери» стали смыслы приватности и публичности родительских практик, которые концептуализируются через идею «территории родительства», основанную на «территориях себя» ('territories of the self') Ирвинга Гофмана (Goffman 1972). Мы рассматриваем, как в дискуссии по поводу описанного выше видеоролика конструируются ее границы, и анализируем, как смыслы, связанные с материнством, влияют на определение и проницаемость этих границ, приватность и публичность родительских практик.

\section{Роль онлайн-практик \\ в конструировании современного родительства}

Родители интересуют интернет-исследователей в основном в связи с тем, как пользуются интернетом дети (Livingstone, Helsper 2008), и как родители ищут информацию и поддержку в сети (Daneback, Plantin 2008; Dworkin et al. 2013). В российском контексте исследователей в большей степени волнуют темы цифровой безопасности и компетентности родителей и детей (Солдатова и др. 2013; Беспалов 2007). Однако существующие исследования показывают значимость родительских онлайн-практик. В онлайн-общении о детях родители не только диверсифицируют представления о воспитании детей и получают поддержку (Pedersen, Lupton 2016), но и производят социальный капитал, который может служить ресурсом для коллективной мобилизации с целью защиты прав сообщества (Чернова, Шпаковская 2011). При этом взаимодействие родителей и гаджетов в некоторых городских пространствах часто подвергается социальному контролю, в том числе со стороны других родителей (Колозариди 2017).

В связи с тем, что забота о детях и ответственность за их воспитание продолжает в основном возлагаться на женщин, материнство имеет смысл рассматривать отдельно от родительства. Анна Шадрина (2017) отмечает, что современный культурный идеал материнства недостижим, но от матерей ожидают соответствия ему. Доминирующая идеология материнства предполагает обязательное удовлетворение от выполнения материнской роли, поэтому женщинам сложно выражать отрицательные эмоции по поводу заботы о ребенке и просить о поддержке (Mamabolo et al. 2009). Поэтому важно обратиться к изучению материнских онлайн-сообществ, которые выступают площадкой для выражения неприемлемых в других контекстах чувств и переживаний по поводу материнства (Микляева, Румянцева 2018). 
Идеал «хорошей матери», который заставляет матерей раз за разом терпеть неудачу в попытках соответствовать ему, проблематизируется в таких пространствах (Pedersen 2016).

Наше исследование выполнено в методологии критического дискурсанализа (Wodak, Meyer 2001). На первом этапе производился отбор, описание и анализ «пространства возможных текстов» выбранной коммуникативной ситуации (публикация на YouTube видео о «плохой матери»). Единицами сбора данных выступили тексты, относящиеся к данной коммуникативной ситуации. Тексты отбирались по принципу максимального насыщения контекстами, акторами, форматами и площадками дискуссии. Учитывалось многообразие медийных ресурсов, фиксировались «следы» репостов. Пространство источников состоит из 30 единиц, разделенных на четыре типа: посты в социальных сетях ВКонтакте и Facebook, в том числе в группах и пабликах (6), обсуждения на форумах (7), публикации в блогах и СМИ (17). Включение разных типов данных обусловлено тем, что в них различается структура дискуссий, которая может влиять на конструирование смыслов в обсуждениях. В СМИ и блогах есть один «центральный» текст и комментарии к нему, основанные на этом тексте. Тексты в СМИ и блогах могут оказывать влияние на аудиторию, в них значимы элементы редакционной и общественной повестки. На форумах первый пост не имеет такого значения, так как он скорее приглашает к обсуждению, чем является самостоятельным высказыванием по теме. Само обсуждение может состоять из нескольких «веток», линий дискуссии, иногда не связанных друг с другом. Интерфейс же социальных сетей предполагает, что в обсуждениях чаще встречаются отдельные комментарии-нарративы и длинные обсуждения внутри одной линии.

На втором этапе проводился сплошной анализ массива текстов методом качественного контент-анализа (Mayring 2014). Публикации в СМИ сначала делились на смысловые блоки (название, «подводка», текст, визуальные элементы и т.д.), а затем внутри смысловых блоков осуществлялась кодировка и анализ текста. В обсуждениях на форумах выделялась структура («корневой» пост и комментарии, отдельные ветки дискуссии), после этого каждое сообщение анализировалось как нарратив. В постах в социальных сетях определялась оригинальность текста, затем производился анализ комментариев как мини-нарративов, учитывалась их «дискурсивная сила» через лайки и ответные комментарии. Анализ позволил выделить основные темы, которые можно определить как дискурсивные оппозиции, через которые конструируется обсуждение: приватное/публичное и мужчина (отец)/женщина (мать). Дальнейшее кодирование велось внутри этих тем. В анализе нет предзаданных кодов и категорий, они выведены индуктивно из данных. Дальнейшая интерпретация и «сборка» смыслов велась в диалоге с теоретическими наработками.

Публикации в СМИ и блогах анализировались и цитировались свободно, однако имя автора ролика скрыто. В работе с форумами и обсуждениями 
в социальных сетях наше исследование имеет этические ограничения, поскольку мы не получали согласия участников обсуждений. Связаться со всеми участниками массовых дискуссий было бы практически невозможно, равно как и отсеивать отказавшихся, так как такие отсеянные тексты все равно влияют на общую динамику обсуждений. Обсуждения в этих источниках можно считать публичными, однако для обеспечения конфиденциальности участников здесь не будут приводиться источники цитат и их авторы.

\section{Динамика и краткое тематическое описание дискуссии}

Динамика дискуссии существенным образом повлияла на смыслы, обнаруженные нами в ходе анализа. В связи с этим мы представляем здесь информацию о том, как развивалось обсуждение, появлялись новые темы и ракурсы дискуссии. Динамика дискуссии по источникам подробно проиллюстрирована (рис.). Кроме видеоролика, на обсуждение наибольшее влияние оказала статья журнала для женщин Cosmopolitan (Грибацкая 2018), которая была первой реакцией СМИ на ситуацию. Именно этот текст дал начало обсуждениям на родительских форумах и в группах ВКонтакте, а похожие издания, прежде всего женские и родительские (Домашний очаг, Daily baby, Мой ребенок, Лиза и др.), публиковали этот материал, ссылались на него, либо повторяли основные идеи. Схожий по тону, но оригинальный новостной контент предложили крупные (Комсомольская правда, АиФ), а также «нишевые» СМИ (например, Правмир.ru и Милосердие.ru).

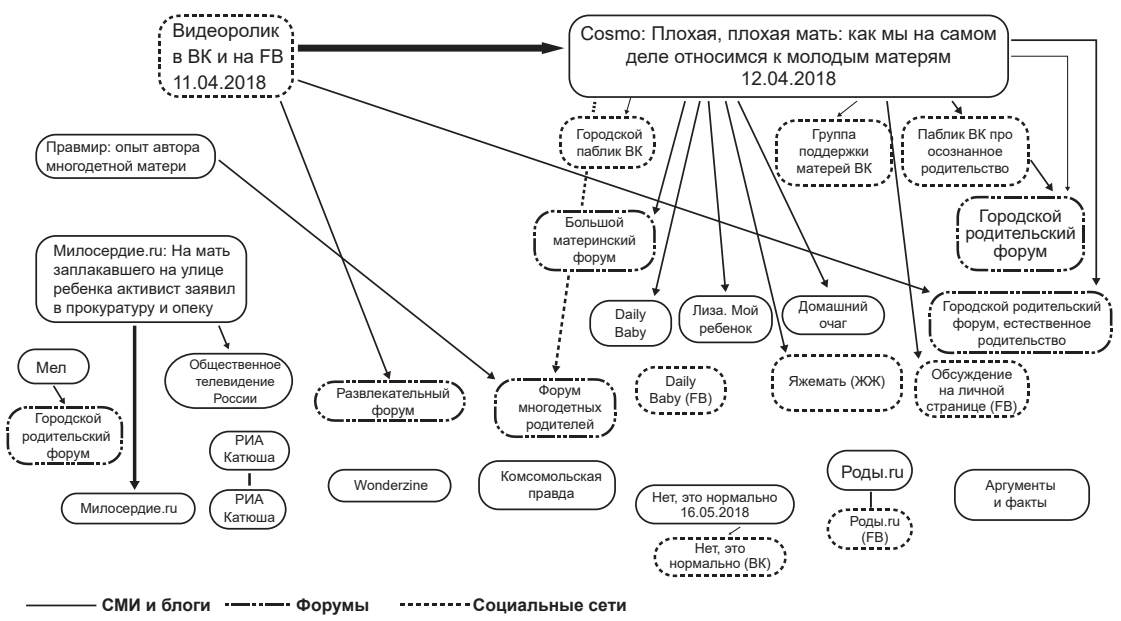

Puс. Дискурсивное пространство онлайн-обсуждения видео о «плохой матери», $11.04-16.05 .2018$ 
Первые публикации в основном интерпретируют кейс как немотивированный акт агрессии по отношению к матери с детьми. Этот ракурс в самом начале дискуссии в социальных сетях провоцирует обмен личными травматичными переживаниями. Компенсируя потери матери, участники обсуждения борются с ним («А можно этого автора привлечь к уголовной ответственности за моральное унижение...?»- 100 «лайков»). Чуть позже событие из разряда новости перешло в объект анализа и обобщений СМИ на тему родительства и материнства в России. Например, автор Wonderzine, вслед за Cosmo, считает публичное порицание матери результатом недружелюбной социальной политики государства в отношении родительства. Ей противопоставляется высокий уровень толерантности к родительству западных стран с демократическим укладом. «КП Ростов», наоборот, заостряет внимание на противостоянии между современной либеральной (основанной на идее личного комфорта) культурой и традиционными ценностями материнства и детства: неудобных матерей демонстративно изгоняют или публично травят («Общество, что с тобой? Тебя тошнит от матерей с детьми?»). РИА «Катюша» использует случай ростовской матери, чтобы показать разрушительное применение ювенальной юстиции, вмешивающейся в частную жизнь семьи.

Обсудив сложившуюся ситуацию, СМИ, зачастую с привлечением экспертов, стали предлагать советы родителям и прохожим в таких случаях. Из подобных стратегий обрисовывается репертуар «приемлемых» реакций: «Не осуждайте, а помогайте: как реагировать на детей, скандалящих на улице» (Милосердие.ru); «Как быть, если вы видите родителя, который никак не может справиться с детской истерикой» (НЭН) и др.

\section{Конструирование «территории родительства»}

В процессе анализа мы отметили, что многие участники обсуждения использовали метафоры географического пространства, говоря о публичности и приватности родительства. Наиболее ярким примером этого является статья интернет-проекта «Нет, это нормально» о «территории родительства» и способах ее отстаивания. Основываясь на таких способах говорения о родительстве и вдохновляясь множественными «территориями себя» Гофмана (Goffman 1972), зависящими от ситуационных и культурных обстоятельств и подверженных различным вмешательствам, мы выстраиваем «территорию родительства» как концептуализацию публичности и приватности родительского опыта на основе обсуждений кейса «плохой матери». Особое внимание мы уделяем тому, как матери определяют границы их территории родительства, отделяющие публичное от приватного, того, что участники обсуждения называют «не их дело»: «необщественное», «негосударственное», что (должно быть) защищено от вмешательства посторонних.

Территория родительства состоит из «зоны родителей» (она приватна, даже если родитель с ребёнком находятся на публике) и «зоны постороннего» 
(от близких родственников до незнакомых людей- «мимокрокодилов»). Зона постороннего всегда публична, именно в ней могут возникать риски нарушения границ территории родительства: осуждения, вмешательство. Экстремальным случаем такого нарушения видится сама онлайн-дискуссия, в ходе которой поведение героини ролика и ее соответствие образу «хорошей матери» обсуждается и оценивается не несколькими случайными встречными, а большим числом интернет-пользователей. Однако даже «зона родителей» не полностью приватна, так как существуют требования к поведению матери: она не должна демонстрировать социально неодобряемое поведение в присутствии ребенка. Ей предписывается контроль эмоций, спокойствие и рациональное поведение. Определенные требования выдвигаются и к детям: выстраиваются границы ситуаций, в которых можно относиться толерантно к крику ребенка, и в которых крик ребенка недопустим:

Помню тему на форуме, когда выложили в сеть орущего в течение всего полета самолета ребенка. И там реакция на того, кто снимал, была с точностью до наоборот: все его поддержали. Ну, почти все... Там замкнутое пространство, ребёнок лезет к чужим людям и мешает им, пугает. Тут улица, ну тащит она его и тащит, через 30 секунд они уже будут далеко (комментарий на материнском форуме).

Ситуация сильного неудобства для окружающих (в самолете) становится одним из случаев допустимого вмешательства посторонних в зону родителя и ребенка- наряду со случаями причинения вреда ребенку (насилие, похищение). Такие ситуации задают один из факторов, определяющих проницаемость «территории родительства».

Другие факторы связаны с дисплеями родителей. Так, по мнению многих комментаторов, присутствие мужчины на месте мамы из ролика или отца ребенка, не привело бы к такой ситуации: (при) мужчине не стали бы делать замечания, не стали бы снимать. В дискуссии неоднократно обращались к роли отца («а где папа?»), который должен был оградить женщину от уязвимой ситуации в публичном пространстве: например, не должен был позволить женщине с детьми выносить мусор. Такие комментарии намекают на гендерную окрашенность приватности и публичности родительства: мужской гендерный дисплей дает своему обладателю неприкосновенность в публичном пространстве, а женский, наоборот, этой неприкосновенности лишает. Следует отметить, что такая реакция созвучна современному запросу общества на «вовлеченное отцовство» (Авдеева 2012). Результаты опросов общественного мнения говорят о возросшей среди россиян тенденции оценивать отцов как «хороших» не столько с позиций традиционных представлений о «кормильце семьи», сколько с позиции активного участия в процессе воспитания и образования ребенка (ВЦИОМ 2019).

Также актуализируется различение между молодыми и многодетными матерями. Молодое материнство описывается как неопытное, когда гра- 
ницы территории родительства еще не установлены и уязвимы для вмешательства; многодетное - как отнимающее много ресурсов у матери, у которой не остается сил для защиты своих границ, с более строгой оценкой окружающих («А зачем тогда рожала?»). В обоих случаях мамы предстают легкими мишенями для критики и вмешательства посторонних людей, они вынуждены соответствовать противоречивым установкам. С точки зрения «опытной мамы» ситуация выглядит менее травмирующей, однако важной для формирования материнского опыта:

И тут к нам подходит старушка: «Нарожала, а справиться не можешь!» Сейчас на эти слова я бы и внимание не обратила, но сейчас-то я в ресурсе, а вот тогда, сразу после родов, они меня очень задели. Я эти слова помню до сих пор, хотя прошло уже 15 лет (комментарий к обсуждению на личной странице в Facebook).

Несмотря на продвигаемый в дискурсе социальной политики положительный образ многодетной матери и в целом позитивное общественное мнение о необходимости поддержки многодетных семей (ФОМ 2016), дискурсивные границы территории многодетной матери в публичных пространствах являются уязвимыми.

\section{Интенсивное материнство: приватные решения и публичное соревнование}

Обсуждения приватности и публичности материнства в анализируемых нами текстах соотносятся с тем, как исследователи характеризуют интенсивное материнство: модель, описанную Шэрон Хэйс (Науs 1996). Одновременно с разговорами об уязвимости матерей в публичном пространстве в дискуссии звучат мнения о том, что кричащий ребенок-исключительно забота матери. Только ей судить, что лучше для ребенка и как себя вести в подобной ситуации: «Это право матери решать, как ей вести себя в случаях детской истерики. А сердобольные прохожие или не в меру ретивые детозащитники пусть идут мимо. Не их дело» (комментарий на материнском форуме). Этот нарратив соотносится с моделью интенсивного материнства, в котором мать- основной поставщик заботы о ребенке (Hays 1996; Douglas, Michaels 2004), в отличие, например, от расширенного материнства, которое подразумевает несколько поставщиков заботы, включая государство (Исупова 2018). Концентрирующая все свои ресурсы на ребенке мать становится наиболее компетентным экспертом, когда дело касается ее чада (Науs 1996).

Однако другие элементы делают интенсивное материнство явно публичным, подверженным оцениванию, в том числе со стороны других матерей: так появляется элемент соревнования между матерями (Douglas, Michaels 2004), который присутствует и в обсуждении видеоролика о «плохой 
матери». Кроме слов поддержки в адрес героини ролика и собственных воспоминаний о подобном опыте, в дискуссиях звучали уверения некоторых женщин в том, что с ними никогда ничего подобного не случилось бы, потому что они прекрасно управляются со своими детьми и контролируют их поведение. Онлайн-нарративы «идеальной матери», в которых происходит негласное соревнование с женщиной из видео и другими участниками обсуждения, делают материнство предметом публичного состязания. При этом также звучат защищающие героиню голоса:

Это не их дело. Пусть за своими детьми и за собой следят и молчат. А то кто-то считает, что вред ребенку наносят газировка и жвачка, кто-то - что ребенок трех лет едет в коляске, а не пешком, третьи считают, что ребенку холодно, а четвертые- что он перекутан (комментарии на материнском форуме).

В этом суждении указывается на множественность и противоречивость взглядов на то, как воспитывать ребенка. Утверждается, что это и создает абсолютную уязвимость матери: она всегда будет не права. В связи с этим возникает запрос на выстраивание непроницаемых границ «территории родительства».

\section{Заключение}

В обсуждении видео о «плохой» ростовской матери сталкиваются различные дискурсы о материнстве и родительстве. В этой статье мы сконцентрировались на том, как участники обсуждения конструировали приватность и публичность родительского и материнского опыта. Территория родительства, ее границы и их проницаемость, варьируются в зависимости от нескольких факторов, ситуационных и статусных. При этом актуализируется проблема защиты этой территории от посторонних: даже дискуссия, в которой большинство участников поддерживает мать, является случаем ее нарушения. Чрезмерная публичность взаимодействий с ребенком ярко проявляется как болевая точка для множества родителей. Такая болезненность и особенная уязвимость матерей, вероятно, связана с доминирующей идеологией интенсивного материнства, которая поощряет обвинение матерей и жесткий спрос с них (Шадрина 2017). Это делает возможной ситуацию вмешательства постороннего в территорию родительства, поскольку материнство становится предметом публичного контроля.

Культурный идеал материнства предполагает публично одобряемое поведение даже в приватном пространстве, если рядом находится ребенок, а в публичном пространстве социальная роль матери оказывается средоточием противоречивых требований и ожиданий. В связи с этим наше исследование позволяет проблематизировать интенсивное материнство, которое доминирует в России (Шадрина 2017), именно с точки зрения 
сочетания факторов приватности и публичности. С одной стороны, ребенок, нарушающий нормы поведения в общественных местах-проблема и забота матери, и она одна должна принимать меры в такой ситуации. С другой, ее решения становятся предметом публичной оценки и даже соревнования со стороны других матерей. Как мы видим из проанализированной дискуссии, это соревнование может происходить в том числе в материнских группах и на онлайн-форумах. Однако онлайн-коммуникация также позволяет матерям выстраивать альтернативный дискурс (мать «никому ничего не должна»), защищать «территорию родительства». Представляется, что исследования «территории родительства» могут быть расширены контекстуальным анализом государственного и правового дискурсов, которые производят собственные схемы оценивания родителей и представления о границах их возможностей и ответственности.

\section{Выражение признательности}

Авторы выражают благодарность лекторам, команде и участникам Онлайншколы интернет-исследований-2018 и Клубу любителей интернета и общества.

\section{Список источников}

Авдеева А. (2012) «Вовлеченное отцовство» в современной России: стратегии участия в уходе за детьми. Социологические исследования, (11): 95-104.

Беспалов Е.И. (2007) Отношение родителей к проблеме агрессивного Интернетконтента. Журнал социологии и социальной антропологии, 10 (3): 160-163

Бороздина Е., Здравомыслова Е., Темкина А. (2012) Как распорядиться «материнским капиталом» или граждане в семейной политике. Социологические исследования, (7): 108-118.

ВЦИОМ (2019) Вовлеченное отцовство, или что для детей важнее денег? Доступно по ссылке: https://wciom.ru/index.php?id=236\&uid=9960 (дата обращения: 23 октября 2019).

Грибацкая С. (2018) Плохая, плохая мать: как мы на самом деле относимся к молодым матерям. Cosmopolitan. Доступно по ссылке: https://www.cosmo.ru/lifestyle/ society/plohaya-plohaya-mat-kak-my-na-samom-dele-otnosimsya-k-molodym-materyam/ (дата обращения: 15 мая 2018).

Исупова О.Г. (2018) Интенсивное материнство в России: матери, дочери и сыновья в школьном взрослении. Неприкосновенный запас, (3): 180-189.

Колозариди П.В. (2017) Родители и гаджеты в большом городе. Шаги, 3 (2): 142-153. Микляева А.В., Румянцева П.В. (2018) «\#Онажемать»: имплицитные социальные представления о материнстве в современном российском интернет-дискурсе. Женщина в российском обществе, 1 (86): 67-77.

НЭН (2018) Как быть, если вы видите родителя, который никак не может справиться с детской истерикой. Доступно по ссылке: https://n-e-n.ru/strugglingparent/ (дата обращения: 3 апреля 2019).

Печерская Н.В. (2012) Мифология родительства: анализ дискурсивного производства идеальной семьи. Журнал исследований социальной политики, 10 (3): 323-342. 
Савинская О.Б. (2011) Забота о детях работающих москвичек. Социологические исследования, (1): 137-142.

Солдатова Г. У., Нестик Т. А., Рассказова Е.И., Зотова Е. Ю. (2013) Цифровая компетентность подростков и родителей. Результаты всероссийского исследования. Москва: Фонд Развития Интернет.

ФОМ (2016) Многодетные семьи. Труднее или легче живется многодетным семьям, чем остальным? Доступно по ссылке: https://fom.ru/Rabota-i-dom/13080 (дата обращения: 1 сентября 2019).

Чернова Ж. В. (2012а) Баланс семьи и работы: политика и индивидуальные стратегии матерей. Журнал исследований социальной политики, 10 (3): 295-308.

Чернова Ж. В. (2012b) Сообщества родителей: новые формы солидарности и ресурсы мобилизации. Женщина в российском обществе, (3): 36-51.

Чернова Ж. В., Шпаковская Л. Л. (2011) Политэкономия современного родительства: сетевое сообщество и социальный капитал. Экономическая соииология, 12 (3): 85-105.

Шадрина А. (2017) Дорогие дети: сокращчение рождаемости и рост «иены» материнства в XXI веке. М.: Новое Литературное Обозрение.

Ярская-Смирнова Е.Р. (2010) Ценностно-символическое пространство семейной политики. Демоскоn Weekly, (409-410).

Daneback K., Plantin L. (2008) Research on Parenthood and the Internet: Themes and Trends. Cyberpsychology: Journal of Psychosocial Research on Cyberspace. Available at: https://cyberpsychology.eu/article/view/4213/3255 (accessed 15 June 2018).

Douglas S. J., Michaels M. W. (2004) The Idealization of Motherhood and How it Has Undermined All Women: The Mommy Myth. New York: Free Press.

Dworkin J., Connell J., Doty J. (2013) A Literature Review of Parents' Online Behavior. Cyberpsychology: Journal of Psychosocial Research on Cyberspace. Available at: https:// cyberpsychology.eu/article/view/4213/3255 (accessed 15 June 2018).

Goffman E. (1972) Relations in Public: Microstudies of the Public Order. Harmondsworth: Penguin.

Hays Sh. (1996) The Cultural Contradictions of Motherhood. New Haven: Yale University Press.

Livingstone S., Helsper E. J. (2008) Parental Mediation of Children's Internet Use. Journal of Broadcasting \& Electronic Media, 52 (4): 581-599.

Mamabolo I., Langa M., Kiguwa P. (2009) To be or not to be a mother: Exploring the notion of motherhood among university students. South African Journal of Psychology, 39 (4): 480-488.

Mayring P. (2014) Qualitative Content Analysis: Theoretical Foundation, Basic Procedures and Software Solution. Available at: https://www.ssoar.info/ssoar/handle/document/39517 (accessed 6 August 2021).

Pedersen S. (2016) The Good, the Bad and the 'Good Enough' Mother on the UK Parenting Forum Mumsnet. Women's Studies International Forum, (59): 32-38.

Pedersen S., Lupton D. (2016) 'What are You Feeling Right Now?' Communities of Maternal Feeling on Mumsnet. Emotion, Space and Society, (26): 57-63.

Rivkin-Fish M. (2010) Pronatalism, Gender Politics, and the Renewal of Family Support in Russia: Toward a Feminist Anthropology of 'Maternity Capital.' Slavic Review, 69 (3): 701-724.

Wodak R., Meyer M. (2001) Methods of Critical Discourse Analysis. London: Sage. 


\section{THE FRONTIERS OF PARENTHOOD: AN ANALYSIS OF THE 'BAD MOTHER' CASE IN SOCIAL MEDIA}

This article explores the private and public dimensions of parenting using a case happened from a Russian regional city in 2018. A man took a smartphone video of a crying child and, adding his own derogatory commentary, uploaded it to the Internet. The case raised intensive discussions in social and mass media. The research deals with the nature of these discussions and how private and public parenting dimensions appeared. Applying critical discourse analysis, the authors examine how the discussion and its agents construct the frontiers of the 'parenthood domain' and mother's social role in public space. The term is borrowed from the publication of one of the parent Internet resources and is interpreted using Goffman's concept 'territory of the self.' The analysed case shows how the dominant ideology of intensive parenting encourages the blaming of mothers. This allows strangers to enter the parenthood domain and public control of mothering. The cultural pattern of mothering assumes publicly accepted behaviour even in private space, where the mother is alone with her child. At the same time, the mother's social role becomes the centre of contradictory demands and expectations in public. Online-discussions become the space of public competition between mothers in terms of intensive mothering. Mass-media associate such discussions with an unfriendly and contradictory state social policy towards parenting. The frontiers of parenting domain depend on the contexts and actors' roles marked not only by space, gender and the roles themselves (mother/stranger), but also by the stages of mastering the role ('young' or 'experienced' mother). The sensitivity and permeability of borders depends on this.

Keywords: parenting, mothering, social media, discourse analysis, online research

DOI: 10.17323/727-0634-2021-19-3-451-464

Oksana Dorofeeva- MSc in Social Sciences, Junior Teacher, Department of Sociology, University of Amsterdam. Email: o.dorofeeva@uva.nl.

Anna Andreeva-Cand. Sci. (Philol.), Assistant Prof., School of Journalism, University of Tyumen, Tyumen, Russian Federation. Email: a.a.andreeva@utmn.ru

Adelia Kaveeva- Doctoral Student, Department of General and Ethnic Sociology, Kazan Federal University, Kazan, Russian Federation. Email: adele.kaveeva@mail.ru

Volha Verbilovich- Lecturer, School of Media, National Research University Higher School of Economics, Moscow, Russian Federation. Email: overbilovich@hse.ru 


\section{References}

Avdeeva A. (2012) 'Vovlechennoe ottsovstvo' v sovremennoy Rossii: strategii uchastiya v ukhode za det'mi ['Involved Fatherhood' in Modern Russia: Strategies for Participating in Child Care]. Sotsiologicheskie Issledovaniia [Sociological Studies], (11): 95-104.

Bespalov E.I. (2007) Otnoshenie roditeley k probleme agressivnogo Internet-kontenta [Parents' Attitude to the Problem of Aggressive Internet Content]. Zhurnal sotsiologii i sotsial'noy antropologii [The Journal of Sociology and Social Anthropology], 10 (3): 160-163.

Borozdina E., Zdravomyslova E., Temkina A. (2012) Kak rasporjadit'sja 'materinskim kapitalom' ili grazhdane v semejnoj politike [How to Manage 'Maternal Capital' or Citizens in Family Policy]. Sociologicheskie issledovanija [Sociological Studies], (7): 108-118.

Chernova Z. (2012a) Soobshchestva roditeley: novye formy solidarnosti i resursy mobilizatsii [Parents Communities: New Forms of Solidarity and Resources for Mobilization]. Zhenshchina v obshchestve [Woman in Russian Society], (3): 36-51.

Chernova Zh. (2012b) Balans sem'i i raboty: politika i individual'nye strategii materej [The Balance of Family and Work: Policies and Individual Strategies of Mothers.]. Zhurnal Issledovanii Sotsial'noi Politiki [The Journal of Social Policy Studies], 10 (3):295-308.

Chernova Z., Shpakovskaya L. (2011) Politekonomiya sovremennogo roditel'stva: setevoe soobshchestvo i sotsial'nyy kapital. [Political Economy of Modern Parenthood: Network Society and Social Capital]. Ekonomicheskaya sotsiologiya [Journal of Economic Sociology], 12 (3): 85-105.

Daneback K., Plantin L. (2008) Research on Parenthood and the Internet: Themes and Trends. Cyberpsychology: Journal of Psychosocial Research on Cyberspace. Available at: https://cyberpsychology.eu/article/view/4213/3255 (accessed 15 June 2018).

Douglas S. J., Michaels M. W. (2004) The Idealization of Motherhood and How it Has Undermined All Women: The Mommy Myth. New York: Free Press.

Dworkin J., Connell J., Doty J. (2013) A Literature Review of Parents' Online Behavior. Cyberpsychology: Journal of Psychosocial Research on Cyberspace. Available at: https:// cyberpsychology.eu/article/view/4213/3255 (accessed 15 June 2018).

FOM (2016) Mnogodetnye sem'i. Trudnee ili legche zhivetsja mnogodetnym sem' jam, chem ostal'nym? [Large Families. Is it More Difficult or Easier for Large Families to Live than the Rest?]. Available at: https://fom.ru/Rabota-i-dom/13080 (accessed 1 September 2019).

Goffman E. (1972) Relations in Public: Microstudies of the Public Order. Harmondsworth: Penguin.

Hays Sh. (1996) The Cultural Contradictions of Motherhood. New Haven: Yale University Press.

Iarskaia-Smirnova E.R. (2010) Tsennostno-simvolicheskoe prostranstvo semeynoy politiki [Value-symbolic Space of Family Policy]. Demoskop Weekly, (409-410).

Isupova O. G. (2018) Intensivnoe materinstvo v Rossii: materi, docheri i synov'ya v shkol'nom vzroslenii. [Intensive Motherhood in Russia: Mothers, Daughters and Sons in School Growing Up]. Neprikosnovennyy zapas. Debaty o politike i kul'ture [Emergency Ration. Debate about Politics and Culture], (3): 180-189. 
Kolozaridi P. V. (2017) Roditeli i gadzhety v bol'shom gorode [Parents and Gadgets in the Big City]. Shagi [Steps], 3 (2): 142-153.

Livingstone S., Helsper E. J. (2008) Parental Mediation of Children's Internet Use. Journal of Broadcasting \& Electronic Media, 52 (4): 581-599.

Mamabolo I., Langa M., Kiguwa P. (2009) To Be or not to Be a Mother: Exploring the Notion of Motherhood among University Students. South African Journal of Psychology, 39 (4): 480-488.

Mayring P. (2014) Qualitative Content Analysis: Theoretical Foundation, Basic Procedures and Software Solution. Available at: https://www.ssoar.info/ssoar/handle/document/39517 (accessed 6 August 2021).

Miklyaeva A. V., Rumyantseva P.V. (2018) '\#Onazhemat': implitsitnye sotsial'nye predstavleniya o materinstve $\mathrm{v}$ sovremennom rossiyskom internet-diskurse ['\#Sheisamother': Implicit Social Beliefs about Motherhood in the Modern Russian Internet Discourse] Zhenshchina v rossiyskom obshchestve [Woman in Russian Society], 1 (86): 67-77.

NEN (2018) Kak byt', esli vy vidite roditelya, kotoryy nikak ne mozhet spravit'sya s detskoy isterikoy [What if You See a Parent Who Can't Cope with Children's Hysteria]. Available at: https://n-e-n.ru/strugglingparent/ (accessed 3 April 2019).

Pecherskaja N.V. (2012) Mifologija roditel'stva: analiz diskursivnogo proizvodstva ideal'noj sem'i [The Mythology of Parenthood: An Analysis of the Discursive Production of an Ideal Family]. Zhurnal Issledovanii Sotsial'noi Politiki [The Journal of Social Policy Studies], 10 (3): 323-342.

Pedersen S. (2016) The Good, the Bad and the 'Good Enough' Mother on the UK Parenting Forum Mumsnet. Women's Studies International Forum, (59): 32-38.

Pedersen S., Lupton D. (2016) 'What are You Feeling Right Now?' Communities of Maternal Feeling on Mumsnet. Emotion, Space and Society, (26): 57-63.

Rivkin-Fish M. (2010) Pronatalism, Gender Politics, and the Renewal of Family Support in Russia: Toward a Feminist Anthropology of 'Maternity Capital.' Slavic Review, 69 (3): 701-724.

Savinskaya O.B. (2011) Zabota o detyakh rabotayushchikh moskvichek [Caring for the Children of Working Muscovites]. Sotsiologicheskie issledovaniya [Sociological Research], (1): $137-142$.

Shadrina A. (2017) Dorogie deti: sokrashchenie rozhdaemosti i rost 'tseny' materinstva $v$ XXI veke [Expensive Children: A Reduction in the Birth Rate and an Increase in the 'Price' of Motherhood in the $21^{\text {st }}$ Century]. Moscow: Novoe Literaturnoe Obozrenie.

Soldatova G.U., Nestik T. A., Rasskazova E. I., Zotova E. Yu. (2013) Tsifrovaya kompetentnost' podrostkov i roditeley. Rezul'taty vserossiyskogo issledovaniya [Digital Competence of Adolescents and Parents. The Results of the All-Russian Study]. Moscow: Foundation for Internet Development.

VCIOM (2019) Vovlechennoe otcovstvo, ili chto dlja detej vazhnee deneg? [Involved Fatherhood, or What is More Important for Children than Money?]. Available at: https:// wciom.ru/index.php?id=236\&uid=9960 (accessed 23 Oktober 2019).

Wodak R., Meyer M. (2001) Methods of Critical Discourse Analysis. London: Sage. 